\title{
Combined Use of C. butyricum Sx-01 and L. salivarius C-1-3 Improves Intestinal Health and Reduces the Amount of Lipids in Serum via Modulation of Gut Microbiota in Mice
}

\author{
Miao Long ${ }^{1}{ }^{\mathbb{D}}$, Shuhua Yang ${ }^{1}$, Peng Li ${ }^{1}$, Xin Song ${ }^{1}$, Jiawen Pan ${ }^{1}$, Jianbin He ${ }^{1}$, Yi Zhang ${ }^{1}$ \\ and Rina $\mathrm{Wu}^{2, *}$ \\ 1 Key Laboratory of Zoonosis of Liaoning Province, College of Animal Science \& Veterinary Medicine, \\ Shenyang Agricultural University, Shenyang 110866, China; longmiao@syau.edu.cn (M.L.); \\ yangshuhua0001@126.com (S.Y.); lipeng79625@163.com (P.L.); 13904227861@126.com (X.S.); \\ panjiawen0101@163.com (J.P.); hejianbin69@163.com (J.H.); sihuo12345@sohu.com (Y.Z.) \\ 2 College of Food Science, Shenyang Agricultural University, Shenyang 110866, China \\ * Correspondence:wrn6956@163.com
}

Received: 30 May 2018; Accepted: 22 June 2018; Published: 24 June 2018

\begin{abstract}
The study was conducted to investigate whether combined use of C. butyricum Sx-01 and L. salivarius C-1-3 could improve the intestinal health and reduce the lipid levels in sera of mice and whether these benefits were related to regulating the intestinal microflora. Eighty Kunming male mice were divided into four groups with five replicates per group and four mice per replicate. Mice in the control group were administrated with $0.2 \mathrm{~mL}$ normal saline; mice in three experimental groups were daily orally administrated with $4 \times 10^{8} \mathrm{cfu}$ of L. salivarius, $4 \times 10^{8} \mathrm{cfu}$ of $C$. butyricum, and a combination thereof $\left(2 \times 10^{8} \mathrm{cfu}\right.$ of L. salivarius, and $2 \times 10^{8} \mathrm{cfu}$ of $C$. butyricum $)$, respectively. The experiment lasted for 14 days. The results showed that the average daily feed intake (ADFI) and feed/gain (F/G) ratio of growing mice underwent no significant changes $(p>0.05)$; however, the average daily gain (ADG) tended to increase over short periods of time. The activities of SOD and GSH-Px in serum in the combination group were significantly increased $(p<0.05)$; The triglyceride, and total cholesterol, contents in serum in the combined treatment group were significantly decreased $(p<0.05)$; The total volatile fatty acids and butyric acid in faecal matter of mice in the experimental groups were all significantly increased at 14 days $(p<0.05)$; The length of villi, and the mucosal thickness of colon and caecum $(p<0.05)$ were significantly improved; The relative abundance of some bacteria with antioxidant capacity or decomposing cholesterol capacity or butyrate producing capacity was increased, while the relative abundance of some pathogenic bacteria was decreased in the colon. Furthermore, our results showed that the beneficial effects of the combined use of the two strains was higher than that of single use. Overall, the results demonstrated that the combined use of C. butyricum Sx-01 and L. salivarius C-1-3 can significantly improve intestinal health and reduce the amount of lipids in sera of mice. The reason for these effects might be that besides their own probiotic effects, combined use of the two strains could regulate the intestinal microflora.
\end{abstract}

Keywords: Lactobacillus salivarius; Clostridium butyricum; blood and biochemical indexes; intestinal microflora; intestinal morphology

\section{Introduction}

Clostridium butyricum (C. butyricum) is a Gram-positive anaerobe species, which can produce butyric-acid and survive at relatively high bile concentrations, lower $\mathrm{pH}$, and temperature; it is 
often found in the gut of healthy humans and animals [1,2]. Most of strains of C. butyricum can produce butyrate, which has the ability to maintain gut immunological homeostasis [3,4] and can, therefore, help the proliferation of intestinal mucosal cells [5]. Certain strains of C. butyricum have often been hypothesised to have beneficial effects of prebiotics. Studies have demonstrated that some strains of $C$. butyricum can promote growth performance of broilers [6,7], balance the intestinal microflora of broiler chickens [3], and improve intestinal morphology [8]. Studies have found that C. butyricum MIYAIRI 588 can treat, and prevent diarrhoea induced by non-antimicrobial agents in rats [9], C. Butyricum CGMCC0313.1 has the ability to modulate colon homeostasis and the lipid profile in obese mice and can stimulate the immune system of mice $[10,11]$, and a specific strain of C. Butyricum has the anti-oxidant and anti-apoptotic ability to exert neuroprotective effects against $I / R$ injury in mice [12]. However, some studies also show that some strains of $C$. butyricum are related to botulism in infants or necrotizing enterocolitis [13].

L. salivarius species, which belongs to the Lactobacillus genus, has gained attention as a promising probiotic species. Certain strains of $L$. salivarius exhibit antibacterial and antifungal properties and have a good health effect on the intestine of mice, rats and humans for the alleviation of intestinal disease [14]. Specific strains of the species have been used to prevent and treat some chronic diseases, such as asthma, cancer and halitosis in humans and to reduce colonization by gastrointestinal (GI) pathogens in animal [15]. Studies showed that heat-killed L. salivarius could protect ftom the liver damage induced by alcohol in rats [16], L. salivarius LI01 exerted a good health-promoting effect in acute liver failure in humans [17]; L. salivarius MTC 1026 could inhibit the adhesion process of some pathogenic bacteria on Caco-2 cells in a competition assay [18]; L. salivarius B1 could elicit local immunomodulatory activities and increase the maturation of the intestinal mucosal immune system of piglets [19]. Although it seems that L. salivarius is safe for consumption by animals and humans. However, there is still a lack of information on the safety of many of the strains as prophylactics in animal and human health.

Although some stains of C. butyricum and L. salivarius have a beneficial effect on the health of the human and animal, it is necessary to carry out relevant tests to determine whether the strains for using as the probiotics is safe. Furthermore, the information is lacking on the effects of the combined use of the two strains on the intestine health. Therefore, we firstly studied the effect of $C$. butyricum sx01, L. salivarius C-1-3, which we had isolated from the health chicken and their combined use on blood and biochemical indices, volatile fatty acids, intestinal morphology in mice, and then studied their effect on intestine microflora. Through our research, we intended to reveal whether the two strains were safe for use and whether the effects of the combination use of them on the intestinal health of mice were related to their ability to modulate the intestinal microflora in mice.

\section{Experimental Section}

\subsection{Probiotic Strains}

Strains C. butyricum Sx-01 and L. salivarius C-1-3 [20] were isolated from the intestine of healthy chicken without being given medicine: they were identified by sequencing PCR-amplified $16 \mathrm{~S}$ rDNA and physiological and biochemical characteristics and stored in our laboratory. The sequence information of the 16S rDNA gene were submitted to the GenBank, and their accession number was MH259843 and KP979479, respectively. The C. butyricum Sx-01 and L. salivarius C-1-3 were stored in broth supplemented with $30 \%(v / v)$ glycerol at $-80{ }^{\circ} \mathrm{C}$. The $1 \%(v / v)$ of C. butyricum Sx-01 or L. salivarius C-1-3 were cultured in Reinforced Clostridium Medium (RCM) broth and in de Man-Rogosa-Sharpe (MRS) broth at $37^{\circ} \mathrm{C}$ for $24 \mathrm{~h}$ respectively before the experiment. The cells were collected after centrifugation $(5000 \times g, 5 \mathrm{~min})$ and washed three times with PBS solution. The cells were resuspended to the final concentration of $1 \times 10^{9}$ viable bacterial cells per $\mathrm{ml}$ PBS. The suspensions were freshly prepared for each administration. 


\subsection{Animals and Treatment}

Some 80 male Kunming mice (body mass $20 \pm 2$ g) were purchased from Liao Ning Chang Sheng Biotechnology Co., Ltd., Benxi, China. The mice were bred in a room at a temperature ranging from 22 to $24{ }^{\circ} \mathrm{C}$ and the mice were subjected to 12-h light/dark cycles and an atmosphere with a relative humidity of from 40 to $60 \%$. Water and diet were provided ad labitum for the mice. The composition of the diets of the mice (\%): corn flour $27 \%$, bran $19 \%$, rice $16 \%$, bean cake $16 \%$, fish powder $13 \%$, calcium power $3 \%$, bone powder $3 \%$, yeast powder $2.3 \%, \mathrm{NaCl} 0.5 \%$, multivitamin $0.1 \%$, trace elements $0.1 \%$. The mice were acclimatised for one week after transportation. The experimental procedures have been approved by the Ethics Committee for Laboratory Animal Care (Animal Ethics Procedures and Guidelines of the People's Republic of China) for the use of Shenyang Agricultural University, China. (Permit No. 264 SYXK<Liao $>2011-0001$ ).

Mice were randomly distributed into four groups, each group had five replicates, and each replicate set contained four mice. Animals within different treatment groups were treated daily by oral gavage (without anaesthesia) at 09:00 and 15:00 for $14 \mathrm{~d}$ as follows: Group A (control group) $=$ administrated with $0.2 \mathrm{~mL}$ of normal saline; Group B (L. salivarius group) = administrated with $0.2 \mathrm{~mL}$ of L. salivarius $\left(1 \times 10^{9} \mathrm{cfu} / \mathrm{mL}\right)$; Group C (C. butyricum group) = administrated with $0.2 \mathrm{~mL}$ of C. butyricum $\left(1 \times 10^{9} \mathrm{cfu} / \mathrm{mL}\right)$; Group D (group of C. butyricum + L. salivarius) $=$ administrated with $0.1 \mathrm{~mL}$ of $L$. salivarius $\left(1 \times 10^{9} \mathrm{cfu} / \mathrm{mL}\right)$ and C. butyricum $\left(1 \times 10^{9} \mathrm{cfu} / \mathrm{mL}\right)$, respectively. Upon intragastric administration on days $0,5,9$, and 14 , the mice mass, the mass gain, feed intake, and mortality were recorded.

\subsection{Blood and Biochemical Indices}

The mice were sacrificed, $24 \mathrm{~h}$ after final treatment, under anaesthesia. Afterwards, we collected the blood samples and separated the serum. Routine blood tests were run to assay the whole blood of mice in each group by using a haematology analyser (HBVet-5 model, Sinnowa, Nanjing, China).

In the experiment, the indices of antioxidation, the biochemical levels of the liver were tested by using commercial kits (Nanjing Jiancheng Bioengineering Institute, Nanjing, China). The details of all determination procedures followed the manufacturer's instructions for the commercial kits (Nanjing Jiancheng Bioengineering Institute, Nanjing, China). SOD was detected by WST-1 method; GSH-ST, GSH-Px were detected by colorimetry method; MDA was detected by TBA method; TC was detected by single-agent GPO-PAP method; TP was measured by Coomassie brilliant blue method; GSH, GOT, GPT were detected by micro-enzyme method; ALB was determined by the bromocresol-chlorine method; and TG was detected by GOD-PAP method.

\subsection{Volatile Fatty Acids Analysis}

For the Volatile fatty acids (VFAs) analysis, the modified method was applied to determine the VFAs concentration in the faeces [21,22]. Firstly, 2-5 g faecal samples were taken and mixed with $\mathrm{KCl}$ solution $(0.4 \mathrm{~mol} / \mathrm{L})$ in an ice-water bath for $2 \mathrm{~min}$, then the supernatants were packed after the samples were centrifuged at $10,000 \mathrm{rpm}$ for $10 \mathrm{~min}$ at $4{ }^{\circ} \mathrm{C}$. The concentrations of VFAs were determined by using an Agilent gas chromatograph. The $5 \mathrm{~mL}$ of the supernatant was added to $2 \mathrm{~mL}$ of $25 \%$ metaphosphoric acid in $3 \mathrm{M}$ sulfuric acid. Total VFAs and three individual VFAs (acetic acid, propionic acid, and butyric acid) were separated and quantified using gas chromatography (Agilent Technologie 7890B GC system, Santa Clara, CA, USA) using a packed glass column DM-FFAP (30 m $\times 250 \mu \mathrm{m} \times 250 \mu \mathrm{m}$, $40-250^{\circ} \mathrm{C}$ ). The external standard method was used for this test. Chromatographically pure grades of acetic acid, propionic acid, and butyric acid were used as mixed standards. Draw a standard curve and calculate the concentration of volatile fatty acids in faces

\subsection{Tissue Sections}

Before conducting routine processing and paraffin embedding, the sections of ileum, colon, and caecum were set in $10 \%$ formalin. According to the methods provided in the reference of Jeong et al. 
(2018) [23], we used hematoxylin and eosin to stain the testis sections and inspected them by using a photomicroscope. Las EZ image pre-processing software was used to measure various intestinal segments of the villus height (VH), width (VW), crypt depth (CD), and mucosal thickness, and then VH/CD was calculated. Data SAS 9.4 was used to analysis these data.

\subsection{Colon Microbial Analysis}

Fresh colon faecal samples from seven mice randomly selected from each group were collected during the final 14 days for colon microbial analysis.

To amplify V3-V4 region of 16S rRNA gene for Illumina deep sequencing, universal primers, 338F:5'-ACTCCTACGGGAGGCAGCA-3' and 806R:5'-GGACTACHVGGGTWTCTAAT-3', were used [24]. The PCR was performed in a total reaction volume of $20 \mu \mathrm{L}: \mathrm{H}_{2} \mathrm{O} 13.25 \mu \mathrm{L}, 10 \times$ PCR ExTaq Buffer $2.0 \mu \mathrm{L}$, DNA template $(100 \mathrm{ng} / \mathrm{mL}) 0.5 \mu \mathrm{L}$, prime1 (10 mmol/L) $1.0 \mu \mathrm{L}$, primer $(10 \mathrm{mmol} / \mathrm{L}) 1.0 \mu \mathrm{L}, \mathrm{dNTP} 2.0 \mu \mathrm{L}$, ExTaq $(5 \mathrm{U} / \mathrm{mL}) 0.25 \mu \mathrm{L}$. After an initial denaturation at $95^{\circ} \mathrm{C}$ for $5 \mathrm{~min}$, an amplification was performed by 30 cycles of incubations for $30 \mathrm{~s}$ at $95^{\circ} \mathrm{C}, 20 \mathrm{~s}$ at $58{ }^{\circ} \mathrm{C}$, and $6 \mathrm{~s}$ at $72{ }^{\circ} \mathrm{C}$, followed by a final extension at $72{ }^{\circ} \mathrm{C}$ for $7 \mathrm{~min}$. Then the amplified products were purified and recovered using 1.0\% agarose gel electrophoresis method. Finally, the library construction and sequencing steps were performed by Beijing Biomarker Technologies Co., Ltd., (Beijing, China).

\subsection{Bioinformatics Analysis}

The bioinformatic analysis in this study was completed at the Biomarker biocloud platform (www.biocloud.org). To obtain the raw tags, paired-end reads were merged by FLASH (v1.2.7, http:/ / ccb.jhu.edu/software/FLASH/) [25]. Then raw tags were filtered and clustered in the next steps. The merged tags were compared to the primers, and the tags with more than six mismatches were discarded by FASTX-Toolkit. Tags with an average quality score $<20$ in a 50-bp sliding window were truncated using Trimmomatic (http: / / www.usadellab.org / cms / ?page=trimmomatic) [26] and tags shorter than $300 \mathrm{bp}$ were removed. We identified possible chimeras by employing UCHIME, a tool included in mothur (http:/ / drive5.com/uchime). The denoised sequences were clustered using Qiime UCLUST module and tags with similarity $\geq 97 \%$ were regarded as an OTU. Taxonomy was assigned to all OTUs by searching against the Silva databases (Release119, http:/ / www.arb-silva.de.) using the RDP classifier within QIIME. The statistical processing of all the data was undertaken using SPSS17.0 software (IBM, Almon, NY, USA). The one-way ANOVA were used to analyse differences between groups and LSD method was used for multiple comparisons. Results were presented as the mean \pm standard error $(\mathrm{X} \pm \mathrm{SE})$. Mean values were proven to be different at $p<0.05$.

\section{Results}

\subsection{Growth Performance}

During the experiments, there were no mice that died or suffered from diarrhoea in any group. As shown in Table 1, the average daily gain and the average daily feed intake were not significantly different between these groups $(p>0.05)$, but the Feed/Gain Ratio in the treated groups showed a downward trend compared with that in the control group.

Table 1. Effect of intragastric administration with C. butyricum Sx-01, L. salivarius C-1-3 and a combination thereof on growth performance of mice.

\begin{tabular}{ccccc}
\hline Index & Group A & Group B & Group C & Group D \\
\hline average daily gain (g) & $0.71 \pm 0.07$ & $0.75 \pm 0.08$ & $0.76 \pm 0.09$ & $0.74 \pm 0.10$ \\
average daily feed intake (g) & $4.77 \pm 0.53$ & $4.82 \pm 0.09$ & $4.47 \pm 0.38$ & $4.77 \pm 0.29$ \\
Feed/Gain Ratio (\%) & $6.73 \pm 1.13$ & $6.49 \pm 0.69$ & $5.96 \pm 1.05$ & $6.51 \pm 0.69$ \\
diarrhea rate (\%) & 0 & 0 & 0 & 0 \\
mortality (\%) & 0 & 0 & 0 & 0 \\
\hline
\end{tabular}




\subsection{Blood Routine Indices}

As shown in Table 2, compared with the control group, the MCV, MCHC, and RDW-SD were significantly different in all treated groups $(p<0.05)$, however, the other indices were not significantly different in all treated groups $(p>0.05)$. These results showed that C. butyricum Sx-01, L. salivarius C-1-3 and their combined use did not change the blood routine indices, which indicated that C. butyricum Sx-01, L. salivarius C-1-3 and their combined use had no adverse effects on blood of mice.

Table 2. Effect of intragastric administration with C. butyricum Sx-01, L. salivarius C-1-3 and a combination thereof on blood indices of mice.

\begin{tabular}{ccccc}
\hline Index & Group A & Group B & Group C & Group D \\
\hline WBC $\left(\times 10^{9} / \mathrm{L}\right)$ & $4.24 \pm 2.04$ & $3.80 \pm 1.93$ & $3.96 \pm 0.99$ & $2.78 \pm 1.55$ \\
LY $(\%)$ & $60.42 \pm 6.25$ & $51.25 \pm 10.27$ & $56.74 \pm 8.02$ & $61.16 \pm 8.23$ \\
MID $(\%)$ & $10.70 \pm 1.15$ & $10.03 \pm 2.61$ & $9.08 \pm 5.85$ & $13.64 \pm 2.46$ \\
GR $(\%)$ & $28.88 \pm 5.55^{\mathrm{ab}}$ & $38.73 \pm 12.35^{\mathrm{a}}$ & $32.38 \pm 7.87^{\mathrm{ab}}$ & $25.20 \pm 6.03^{\mathrm{b}}$ \\
LY $\left(\times 10^{9} / \mathrm{L}\right)$ & $2.48 \pm 1.04$ & $1.98 \pm 1.05$ & $2.24 \pm 0.66$ & $1.24 \pm 1.04$ \\
MID $\left(\times 10^{9} / \mathrm{L}\right)$ & $0.48 \pm 0.27$ & $0.38 \pm 0.21$ & $0.42 \pm 0.15$ & $0.38 \pm 0.22$ \\
GR $\left(\times 10^{9} / \mathrm{L}\right)$ & $1.28 \pm 0.80$ & $1.45 \pm 0.84$ & $1.20 \pm 0.51$ & $0.76 \pm 0.47$ \\
RBC $\left(\times 10^{12} / \mathrm{L}\right)$ & $8.03 \pm 1.22$ & $7.29 \pm 2.68$ & $7.74 \pm 2.28$ & $7.75 \pm 2.93$ \\
HGB $(\mathrm{g} / \mathrm{L})$ & $129.80 \pm 24.31$ & $126.25 \pm 33.94$ & $122.00 \pm 34.95$ & $121.80 \pm 42.77$ \\
HCT $(\%)$ & $44.13 \pm 6.32$ & $36.57 \pm 14.00$ & $37.12 \pm 10.15$ & $36.72 \pm 13.71$ \\
MCV (fL) & $55.13 \pm 2.24^{\mathrm{a}}$ & $49.90 \pm 1.57^{\mathrm{b}}$ & $48.48 \pm 2.83^{\mathrm{b}}$ & $47.70 \pm 2.70^{\mathrm{b}}$ \\
MCH $(\mathrm{Pg})$ & $15.10 \pm 0.80$ & $16.30 \pm 1.49$ & $15.76 \pm 0.25$ & $15.98 \pm 1.09$ \\
MCHC (g/L) & $275.25 \pm 23.47^{\mathrm{b}}$ & $328.67 \pm 40.20^{\mathrm{a}}$ & $327.40 \pm 15.95^{\mathrm{a}}$ & $336.40 \pm 18.90^{\mathrm{a}}$ \\
RDW-CV $(\%)$ & $18.93 \pm 4.50$ & $16.63 \pm 1.56$ & $16.26 \pm 1.42$ & $14.68 \pm 4.24$ \\
RDW-SD (fL) & $45.10 \pm 7.43^{\mathrm{a}}$ & $34.67 \pm 2.71^{\mathrm{b}}$ & $32.50 \pm 0.92^{\mathrm{b}}$ & $33.02 \pm 1.48^{\mathrm{b}}$ \\
PLT $\left(\times 10^{9} / \mathrm{L}\right)$ & $426.80 \pm 143.29$ & $281.33 \pm 86.01$ & $310.20 \pm 123.43$ & $338.80 \pm 104.37$ \\
MPV (fL) & $8.24 \pm 0.76$ & $7.63 \pm 0.32$ & $8.18 \pm 1.90$ & $7.42 \pm 0.35$ \\
PDW (fL) & $10.95 \pm 3.32$ & $9.30 \pm 1.56$ & $8.00 \pm 2.71$ & $7.78 \pm 1.52$ \\
PCT $(\%)$ & $0.34 \pm 0.13$ & $0.21 \pm 0.08$ & $0.26 \pm 0.13$ & $0.25 \pm 0.08$ \\
\hline
\end{tabular}

Note: WBC, white blood cell; LY, lymphocytes; MID, median cell; GR, granulocyte; RBC, red blood cell; HGB, Hemoglobin; HCT, hematocrit; MCV, mean corpusular hemoglobin; $M C H$, mean corpusular hemoglobin; MCHC, mean corpusular hemoglobin concentration; RDW-CV, red blood cell volume distribution width-Coefficient of Variation; RDW-SD, red blood cell volume distribution width-standard deviation; PLT, blood platelet; MPV, Meanplateletvolume; PDW, Platelet distribution width; PCT, thrombocytocrit. On the corner of different letters differed significantly $(p<0.05)$, without superscript or marked with the same letter angle has no significant difference $(p>0.05)$.

\subsection{Serum Index}

As shown in Table 3, compared with the control group, the activity of total SOD in serum in group B was significantly increased $(p<0.05)$, and the activities of the total SOD, GSH-Px, and the contents of GSH in the serum in group C were significantly increased $(p<0.05)$; however, there was no significant difference between these two test groups $(p>0.05)$. Compared with the control group, group B and group C, the activities of the total SOD, GSH-Px, GSH-ST, and the amount of GSH in the serum in group $\mathrm{D}$ were higher than these in the other three groups $(p<0.05)$. Compared with the control group, the amounts of TC and TG in group D were lower than that in Group A (control group). These results showed that C. butyricum, L. salivarius and their combined use did not damage the liver, and the combined use of the two strains could significantly improve the antioxidant capacity and reduced the contents of TC and TG of mice. 
Table 3. Effect of intragastric administration with C. butyricum Sx-01, L. salivarius C-1-3 and a combination thereof on blood indices of mice.

\begin{tabular}{ccccc}
\hline Index & Group A & Group B & Group C & Group D \\
\hline T-SOD (U/mL) & $99.276 \pm 5.752^{\mathrm{b}}$ & $104.649 \pm 4.444^{\mathrm{a}}$ & $107.227 \pm 5.128^{\mathrm{a}}$ & $110.336 \pm 5.150^{\mathrm{c}}$ \\
GSH-ST (U/mL) & $17.521 \pm 0.676^{\mathrm{a}}$ & $17.982 \pm 2.457^{\mathrm{a}}$ & $18.990 \pm 1.525^{\mathrm{a}}$ & $20.978 \pm 1.642^{\mathrm{b}}$ \\
GSH-Px (U/mL) & $663.334 \pm 74.437^{\mathrm{b}}$ & $678.222 \pm 77.299^{\mathrm{ab}}$ & $734.222 \pm 65.212^{\mathrm{a}}$ & $749.618^{\mathrm{b}} \pm 70.621^{\mathrm{c}}$ \\
GSH (umol/L) & $24.568 \pm 1.985^{\mathrm{b}}$ & $25.828 \pm 3.079^{\mathrm{ab}}$ & $27.635 \pm 3.473^{\mathrm{a}}$ & $29.898^{\mathrm{b}} \pm 2.275^{\mathrm{c}}$ \\
MDA (nmol/mL) & $6.085 \pm 1.389^{\mathrm{a}}$ & $5.662 \pm 1.257^{\mathrm{ab}}$ & $4.763 \pm 1.193^{\mathrm{b}}$ & $4.754 \pm 1.291^{\mathrm{b}}$ \\
ALB (g/L) & $16.850 \pm 1.228^{\mathrm{ab}}$ & $17.290 \pm 1.073^{\mathrm{a}}$ & $16.018 \pm 0.947^{\mathrm{ab}}$ & $15.960 \pm 1.836^{\mathrm{b}}$ \\
TP (g/L) & $31.263 \pm 2.605$ & $32.180 \pm 2.623$ & $30.336 \pm 1.938$ & $30.970 \pm 2.394$ \\
GLO (g/L) & $14.413 \pm 1.547^{\mathrm{b}}$ & $14.890 \pm 1.838$ & $14.318 \pm 1.160$ & $15.010 \pm 1.323$ \\
AST (U/L) & $59.938 \pm 14.961$ & $55.720 \pm 5.466$ & $54.936 \pm 10.593$ & $60.880 \pm 12.438$ \\
ALT (U/L) & $25.325 \pm 7.117^{\mathrm{a}}$ & $22.060 \pm 3.858^{\mathrm{ab}}$ & $21.364 \pm 8.026^{\mathrm{a}}$ & $19.210 \pm 2.937^{\mathrm{b}}$ \\
TC (mmol/L) & $1.361 \pm 0.071^{\mathrm{a}}$ & $1.394 \pm 0.334^{\mathrm{a}}$ & $1.285 \pm 0.206^{\mathrm{a}}$ & $1.071 \pm 0.033^{\mathrm{b}}$ \\
TG (mmol/L) & $1.198 \pm 0.371^{\mathrm{a}}$ & $0.956 \pm 0.224^{\mathrm{a}}$ & $1.189 \pm 0.263^{\mathrm{a}}$ & $0.861 \pm 0.280^{\mathrm{b}}$ \\
\hline
\end{tabular}

Note: On the corner of different letters differed significantly $(p<0.05)$, without superscript or marked with the same letter angle has no significant difference $(p>0.05)$.

\subsection{VFAs}

As shown in Tables 4-7, the concentration of the acetic acid, propanoic acid, butyric acid, and total VFAs in the four groups before intragastric administration were not significantly different $(p>0.05)$. When the mice were treated, by intragastric administration, with L. salivarius Sx-01, C. butyricum C-1-3 and their mixture respectively, the butyric acid and the total VFAs were all increased on days 5, 9, and 14 , and compared with the control group, the butyric acid levels in groups C and D were significantly increased $(p<0.05)$. These results showed that the combined use of the two strains could increase the butyric acid levels and the total VFAs.

Table 4. Effect of intragastric administration with C. butyricum Sx-01, L. salivarius C-1-3 and a combination thereof on blood excrement Volatile fatty acids (VFAs) concentration of mice (Day 0).

\begin{tabular}{lcccc}
\hline & Acetic Acid & Propanoic Acid & Butyric Acid & Total VFAs \\
\hline Group A & $53.04 \pm 7.24$ & $11.17 \pm 1.27$ & $4.92 \pm 0.27$ & $69.13 \pm 8.61$ \\
Group B & $48.08 \pm 1.84$ & $10.36 \pm 1.32$ & $5.01 \pm 1.74$ & $63.45 \pm 3.92$ \\
Group C & $47.86 \pm 4.19$ & $11.74 \pm 1.56$ & $4.99 \pm 1.09$ & $64.59 \pm 5.80$ \\
Group D & $47.27 \pm 3.57$ & $9.13 \pm 0.60$ & $6.68 \pm 1.25$ & $63.08 \pm 5.41$ \\
\hline
\end{tabular}

Table 5. Effect of intragastric administration with C. butyricum Sx-01, L. salivarius C-1-3 and a combination thereof on blood excrement VFAs concentration of mice (Day 5).

\begin{tabular}{lcccc}
\hline & Acetic Acid & Propanoic Acid & Butyric Acid & Total VFAs \\
\hline Group A & $47.88 \pm 1.45$ & $9.76 \pm 0.14^{\mathrm{b}}$ & $4.60 \pm 0.44^{\mathrm{c}}$ & $62.25 \pm 1.88$ \\
Group B & $49.95 \pm 5.06$ & $11.27 \pm 1.68^{\mathrm{ab}}$ & $4.76 \pm 0.58^{\mathrm{c}}$ & $65.98 \pm 7.24$ \\
Group C & $52.00 \pm 5.48$ & $11.99 \pm 1.08^{\mathrm{a}}$ & $7.75 \pm 0.49^{\mathrm{a}}$ & $71.74 \pm 7.05$ \\
Group D & $50.36 \pm 1.83$ & $10.55 \pm 0.65^{\mathrm{ab}}$ & $7.70 \pm 0.43^{\mathrm{a}}$ & $68.61 \pm 1.30$ \\
\hline
\end{tabular}

Note: On the corner of different letters differed significantly $(p<0.05)$, without superscript or marked with the same letter angle has no significant difference $(p>0.05)$.

Table 6. Effect of intragastric administration with C. butyricum Sx-01, L. salivarius C-1-3 and a combination thereof on blood excrement VFAs concentration of mice (Day 9).

\begin{tabular}{ccccc}
\hline & Acetic Acid & Propanoic Acid & Butyric Acid & Total VFAs \\
\hline Group A & $49.12 \pm 0.19^{\mathrm{b}}$ & $9.46 \pm 0.22^{\mathrm{c}}$ & $4.99 \pm 0.90^{\mathrm{b}}$ & $63.57 \pm 1.18^{\mathrm{b}}$ \\
Group B & $48.31 \pm 3.17^{\mathrm{b}}$ & $10.52 \pm 0.94^{\mathrm{bc}}$ & $5.46 \pm 1.42^{\mathrm{b}}$ & $64.28 \pm 5.37^{\mathrm{b}}$ \\
Group C & $65.22 \pm 6.43^{\mathrm{a}}$ & $15.00 \pm 3.24^{\mathrm{a}}$ & $8.14 \pm 1.85^{\mathrm{a}}$ & $88.36 \pm 11.53^{\mathrm{a}}$ \\
Group D & $65.26 \pm 3.08^{\mathrm{a}}$ & $13.55 \pm 1.07^{\mathrm{ab}}$ & $8.70 \pm 0.75^{\mathrm{a}}$ & $87.52 \pm 4.20^{\mathrm{a}}$ \\
\hline
\end{tabular}

Note: On the corner of different letters differed significantly $(p<0.05)$, without superscript or marked with the same letter angle has no significant difference $(p>0.05)$. 
Table 7. Effect of intragastric administration with C. butyricum Sx-01, L. salivarius C-1-3 and a combination thereof on blood excrement VFAs concentration of mice (Day 14).

\begin{tabular}{ccccc}
\hline & Acetic Acid & Propanoic Acid & Butyric Acid & Total VFAs \\
\hline Group A & $73.77 \pm 25.84$ & $12.44 \pm 4.48$ & $8.35 \pm 0.27^{\mathrm{b}}$ & $88.56 \pm 30.21^{\mathrm{b}}$ \\
Group B & $74.33 \pm 27.26$ & $16.38 \pm 3.57$ & $12.13 \pm 3.68^{\mathrm{ab}}$ & $102.85 \pm 34.42^{\mathrm{ab}}$ \\
Group C & $75.63 \pm 23.59$ & $17.92 \pm 5.32$ & $14.32 \pm 2.75^{\mathrm{a}}$ & $107.87 \pm 31.66^{\mathrm{a}}$ \\
Group D & $76.87 \pm 22.36$ & $16.65 \pm 3.95$ & $14.39 \pm 2.35^{\mathrm{a}}$ & $105.81 \pm 28.60^{\mathrm{a}}$ \\
\hline
\end{tabular}

Note: On the corner of different letters differed significantly $(p<0.05)$, without superscript or marked with the same letter angle has no significant difference $(p>0.05)$.

\subsection{Effect on Intestinal Morphological Structure}

As shown in Figure 1A, compared with the control group, the villous length of the ileum was significantly increased in the L. salivarius group, C. butyricum group and with treatment by the combination thereof. The villous length was increased more significantly $(p<0.05)$ in the combined treatment group, the intestinal crypt was decreased in the L. salivarius group and in the combinedtreatment group $(p<0.05)$; however, the widths of the intestinal villi were not significantly different in these groups $(p>0.05)$. When the mice were treated by intragastric administration of L. salivarius, C. butyricum, or a combination thereof, the ratio of $\mathrm{VH} / \mathrm{CD}$ was significantly higher $(p<0.05)$. As shown in Figure 1B, the number of villi in the combined treatment group was significantly increased, and the arrangement was more orderly than that in the control group. These results showed that the combined use of the two strains could enhance the intestine health.
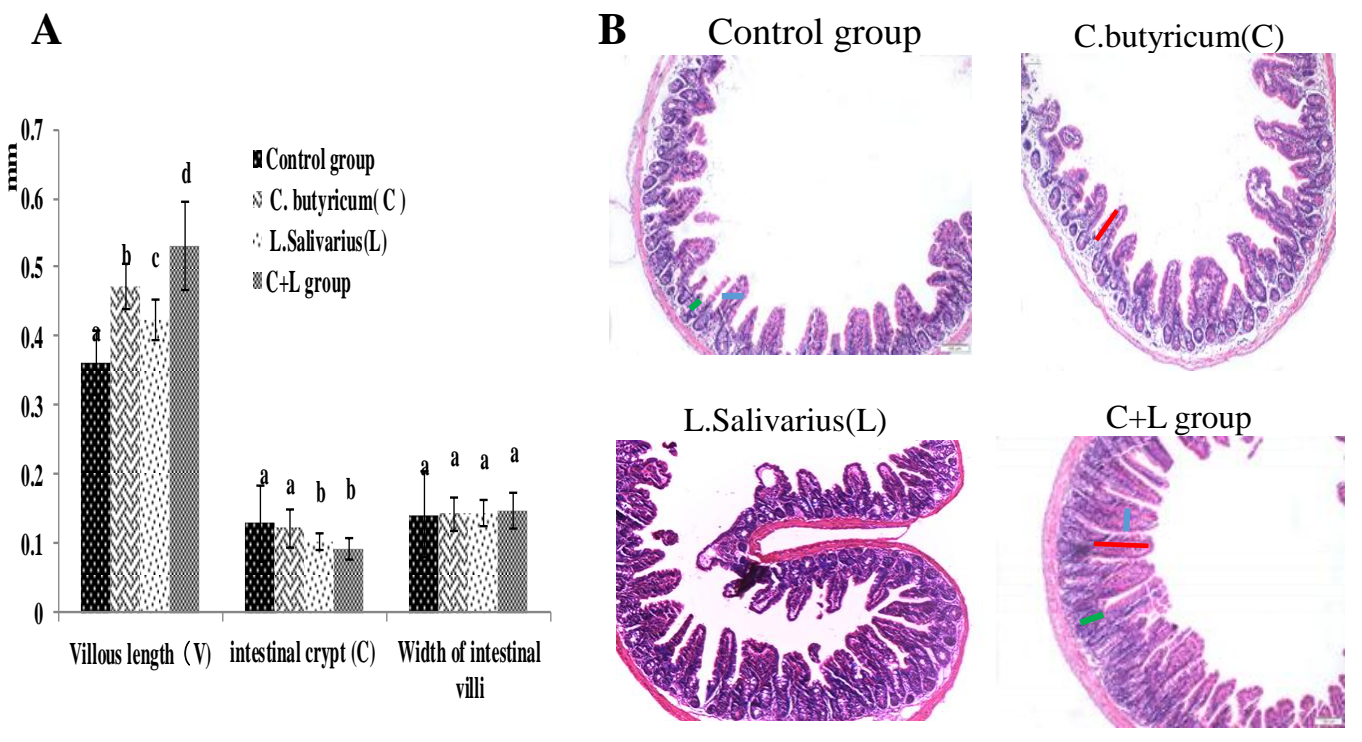

Figure 1. The villous length, intestinal crypt, width of intestinal villi and the ileum slice $(\mathrm{HE} 10 \times 10)$ in different groups. (A) The villous length, intestinal crypt, width of intestinal villi; the ileum slice (B) the ileum slice $($ HE $10 \times 10)$ in control group, L. salivarius group, C. butyricum group and combined treatment group. Red line represents villous length, green line represents intestinal crypt depth, blue line represents villi width. Note: On the column of different letters differed significantly $(p<0.05)$, without superscript or marked with the same letter angle has no significant difference $(p>0.05)$.

As shown in Figure 2A, the mucosal thickness of the caecum in the combined treatment group was significantly higher than that in the control group, L. salivarius group, and C. butyricum group $(p<0.05)$. Compared with the control group, the mucosal thickness of the colon in the L. salivarius group, C. butyricum group, and the combined treatment group was increased $(p<0.05)$. As shown in Figure 2B, the mucosal thickness of the colon in the combined treatment group was significantly increased, and the arrangement was more orderly than that in the control group. 
A

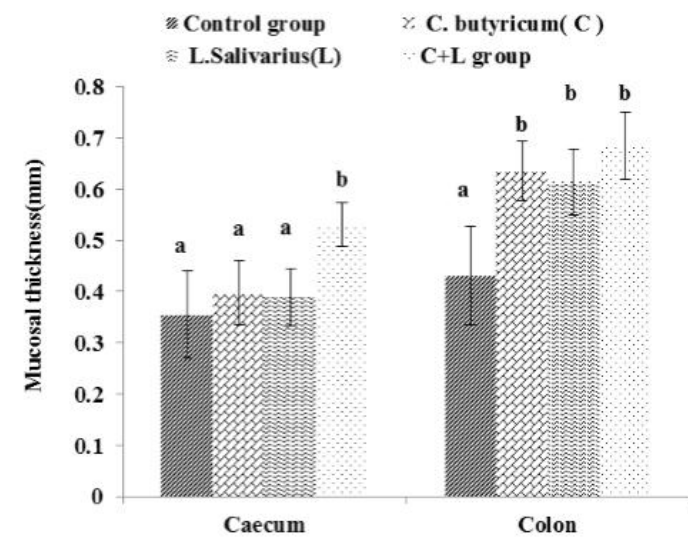

B

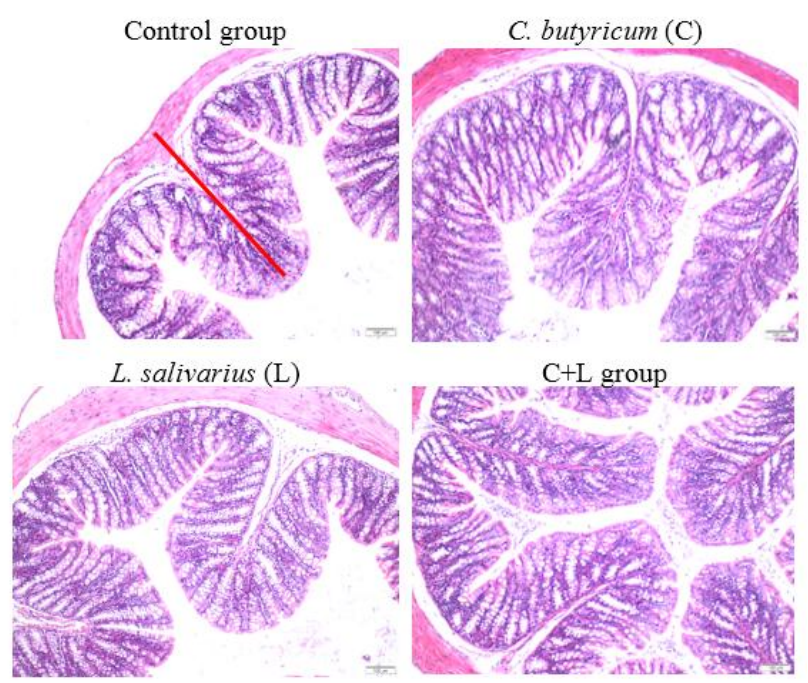

Figure 2. The mucosal thickness of caecum and colon and the colon slice $(\mathrm{HE} 10 \times 10)$ slice $(\mathrm{HE} 10 \times 10)$ in different groups. (A) The mucosal thicknessm; (B) the ileum slice (HE $10 \times 10)$ in control group, L. salivarius group, C. butyricum group and combined treatment group. Red line represents mucosal thickness. Note: On the column of different letters differed significantly $(p<0.05)$, without superscript or marked with the same letter angle has no significant difference $(p>0.05)$.

\subsection{Effects of L. salivarius, C. butyricum, and Their Combined, Use on the Colon Microbiota}

A beta diversity map based on the Bray-Curtis algorithm (Figure 3) showed that the similarity in species diversity is very different when two strains are given to mice. The results indicated that C. butyricum and its combined use with $L$. salivarius could change the species diversity of bacteria in the colon of mice.

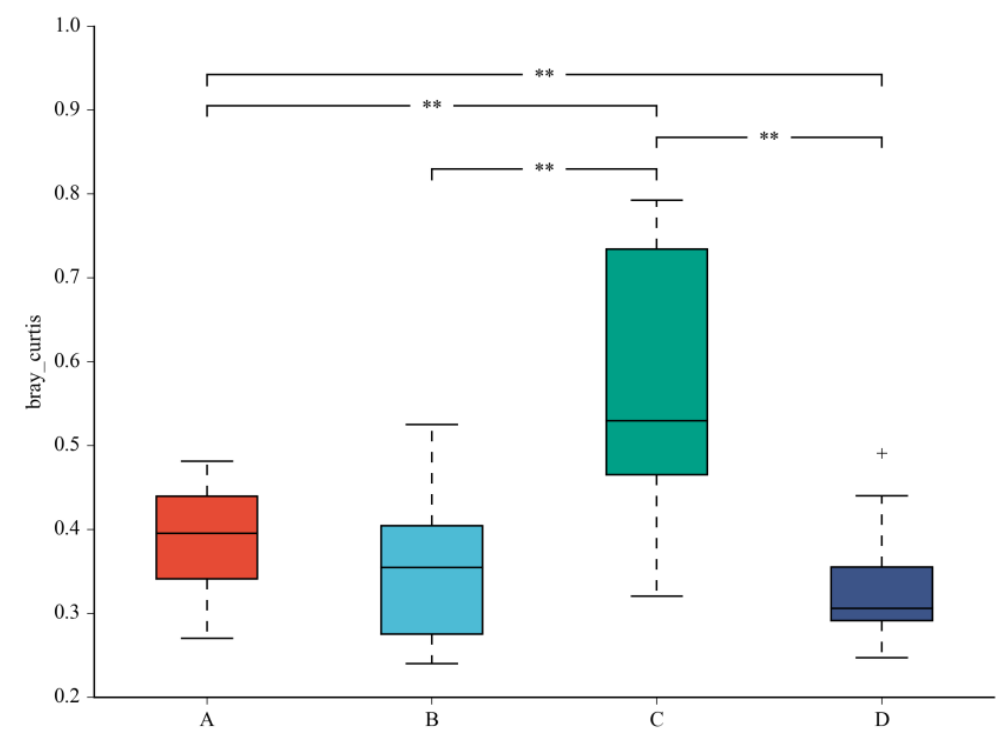

Figure 3. Beta diversity map based on the Bray-Curtis algorithm. Abscissa indicates group; ordinate indicates distance; boxes of different colors represent groups. ${ }^{*}$ Significant difference between groups $(p<0.01)$. The taxonomic biomarkers (LDA score $>2)$ in the colon microbial communities of the four groups were identified by LEfSe method (Figure 4A,B). As shown in Figure 4A,B, LEfSe detected a marked increase (LDA score $>2$ ) in the relative abundance of the Eubacterium_coprostanoligenes_group genus and Peptococcaceae family in the mice of the combined treatment group compared with other groups. "+" stand for outlier. 

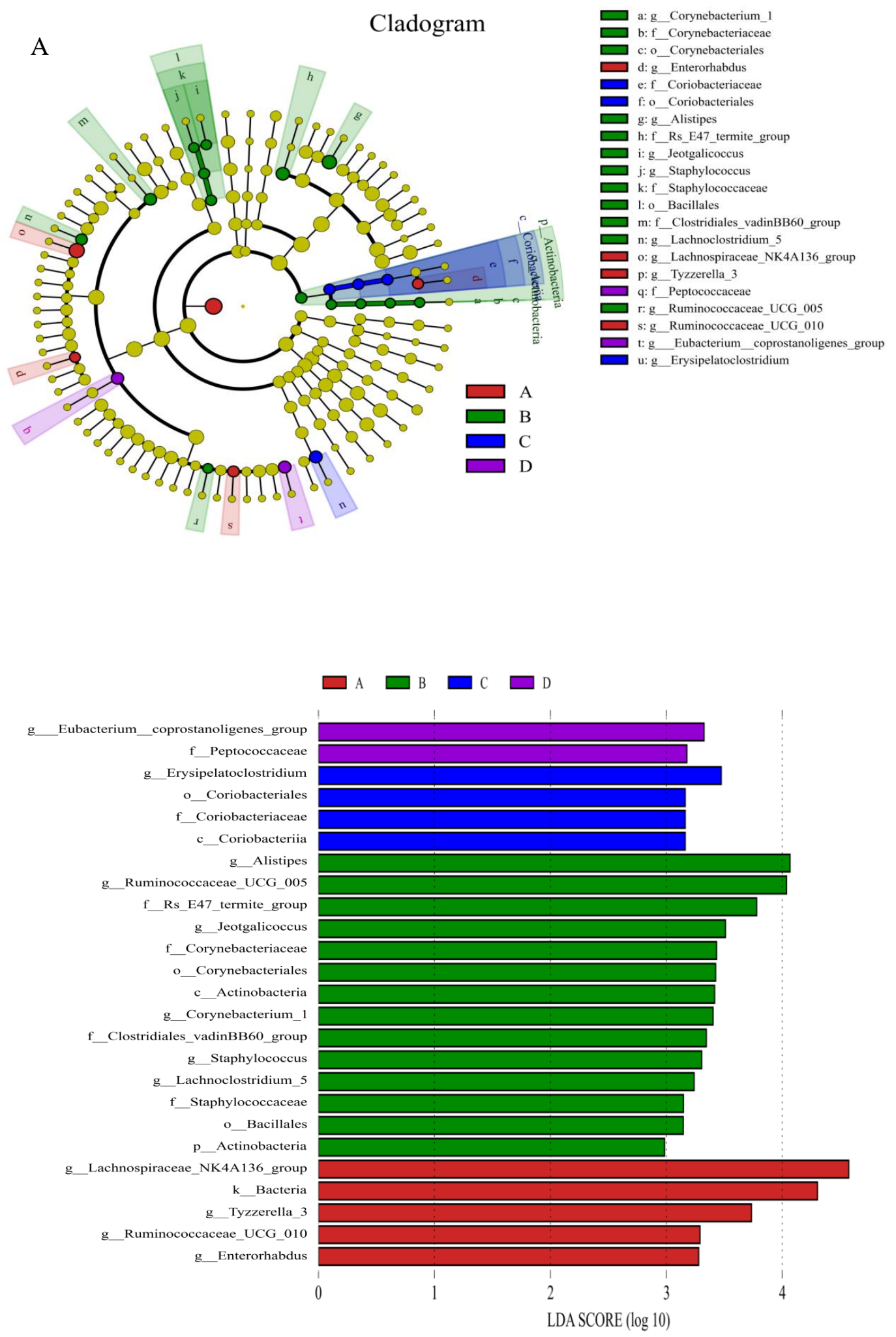

Figure 4. Diversity and composition of colon microbiota. LEfSe results in the four groups, representing the relevant features on taxonomic trees (A) and Key phylotypes in the colon responding to treatments were identified by the LEfSe algorithm (B). (A) Control group; (B) L. salivarius group; (C) C. butyricum group; (D) Combined treatment group. 
The relative abundances of the genus Eubacterium_coprostanoligenes_group (Figure 5A) and family Clostridiales_vadinBB60_group (Figure 5B) were significantly (LDA score $>2$ ) higher in group $\mathrm{D}$ than in the control group; however, the relative abundance of the genus Enterorhabdus (Figure 5C) and Tyzzerella (Figure 5D) was significantly (LDA score $>2$ ) lower in group D than in the other groups; the relative abundance of Staphylococcus (Figure 5E), Corynebacterium (Figure 5F) and Bacteroidales-f__Rs_E47_termite_group (Figure 5G) was (LDA score > 2) lower in group D than that in group A (the control group).
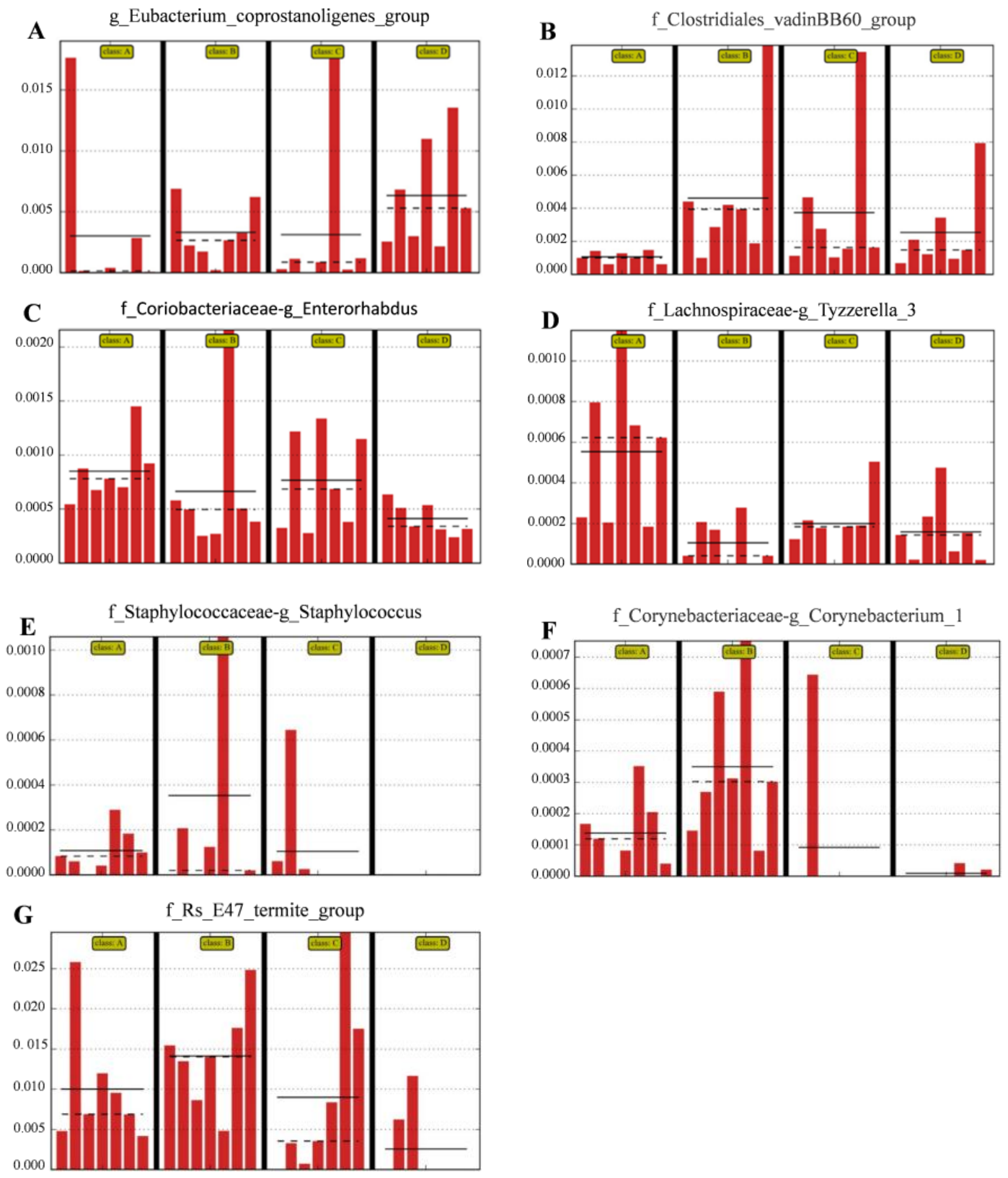

Figure 5. Compared with control group, the histograms indicate the higher relative abundance of the genus Eubacterium_coprostanoligenes_group (A) and family Clostridiales_vadinBB60_group (B) and the lower relative abundance of the genus Enterorhabdus (C), Staphylococcus (E), Corynebacterium_1 (F) and Bacteroidales-f_Rs_E47_termite_group (G) in the colon microbiota of the group D. (A) Control group; (B) L. salivarius group; (C) C. butyricum group; (D) Combined treatment group. 


\section{Discussion}

Previous studies showed that combined administration of probiotic stains of B. subtilis and $L$ acidophilus to weaning rabbits could improve the growth performance, cecal fermentation and number of gut beneficial bacteria populations [27]; the supplementation of B. subtilis, C. butyricum and L. acidophilus together improved growth performance, nutrient digestibility, and gut health in broilers [28]; the supplementation of Bacillus, Saccharomyces and lactic acid bacteria (LAB) had positive effects on growth, feed conversion and nutrient digestibility in grower pigs and increased faecal LAB counts and decreased faecal E. coli counts in the grower pigs [29]. These results indicated that combined use of probiotic could increase animal production and to a certain extent, the probiotic effects were related to the regulation of gut microbiota. However, there is no report on the prebiotic effect of combining the use of strains of C. butyricum and and L. salivarius.

In our study, we firstly confirmed the safety of C. butyricum Sx-01 and L. salivarius C-1-3 from the results of blood biochemical and then found that the combined use of the two strains could improve intestinal health and reduce blood lipids, which might be related to their regulating intestinal flora besides their own probiotic effects.

In our tests, the mice were given $4 \times 10^{8}$ cfu of the two strains per day. The dosage was close to most experiments in mice $[2,12,16,30,31]$. The safety of $C$. butyricum was vitally important. In our tests, $C$. butyricum Sx-01 did not show any toxicological effects in mice as there were no adverse effects on the blood and biochemical indices at the oral dosage with $4 \times 10^{8} \mathrm{cfu}$ to the mice. Furthermore, the C. butyricum Sx-01 strain was separated from the healthy and untreated chicken intestines, while toxigenic strains of $C$. butyricum were often found in pathological conditions, such as botulism in infants or necrotizing enterocolitis in neonates [13,32-34]. Until now, L. salivarius does not pose a health risks to animals or humans in the doses currently used for a variety of applications [15]. Our results also showed that L. salivarius C-1-3 was safe to use as it had no adverse effects on the blood and biochemical indices and could improve intestinal health. Combined with our previous study, L. salivarius C-1-3 had the characters of the acid, bile and high temperature resistance and had a powerful antibacterial effect against E. coli, Salmonella and Staphylococcus aureus [20]; it could be considered as a probiotic.

In recent years, some studies showed that combined use of probiotics could promote growth performance in animals [35-38]. However, some research showed that combined use of probiotics exerted no significant effect on growth performance [39]. Our results found that compared with control, the effect of C. butyricum Sx-01, L. salivarius C-1-3, and their combined use on the growth performance of mice was not significant, but the average daily gain and feed utilisation showed an increasing trend. The inconsistency might be related to the strains of probiotic, administration dosage, diet composition, the experimental duration and experimental animals. Therefore, in the next step, the experimental design should be extended to give other animals different dosages and observe any longer-term effects.

Our results showed that the average haemoglobin concentration in the serum of mice increased when the mice were given C. butyricum Sx-01, or L. salivarius C-1-3. These results might be that these two probiotics enhance the circulation of oxygen in mice and enhance the metabolic function of mice. However, the mechanisms need to be further studied.

Studies have shown that probiotics can enhance antioxidant ability [40,41]. Consistent with our results, the findings showed that serum antioxidant abilities were significantly enhanced while using L. plantarum [42], L. johnsonii BS15 [43] and yeast [44]. Our results showed that when mice were given C. butyricum and L. salivarius, the activities of SOD, GSH-Px in the serum were increased, and the MDA content was decreased. SOD and GSH-Px are important enzymes in the defence against oxidative stress and MDA is the main product of polyunsaturated lipid peroxidation. Previous studies have demonstrated that some strains of $C$. butyricum and L. salivarius can decrease the oxidative state by enhancing the levels of the activities of SOD and GSH-Px and decreasing the level of MDA to reduce the production of reactive oxygen species (ROS) $[45,46]$. The mechanism of antioxidation may be that the SOD and GSH produced by Lactobacillus can scavenge hydroxyl radicals and hydrogen peroxide [47] and butyrate and $\mathrm{H}_{2}$ produced by $\mathrm{C}$. butyricum have beneficial effects on reduction of 
oxidative stress [48]. Our results further proved that the two probiotics could improve the antioxidant capacity and also demonstrated that improving the antioxidant capacity by combining the use of the two strains was better than their single use. The reason could be that when combining use of the two strains, the antioxidant capacity was superimposed.

Our results showed that upon administration of mice with the mixture of C. butyricum Sx-01 and L. salivarius C-1-3, the triglyceride, and glycaemic, indices were significantly reduced in the serum compared with those in the control, and single-use groups. One reason for this might be that some strains of Lactobacillus had beneficial effects on glycaemic control, triglycerides, and VLDL cholesterol concentrations $[49,50]$ and C. butyricum could decrease plasma and hepatic cholesterol levels in cholesterol-fed rats [10]. When the two species were administrated together to the mice, they could play a synergistic role in retarding cholesterol synthesis or increasing degradation of cholesterol by gut bacterial enzymes [45,51]. Interestingly, we found that the two probiotics, in combined use, enhanced the relative abundance of the genus Eubacterium_coprostanoligenes_group, by which cholesterol could be decomposed into faecal sterols that were not absorbed but were excreted in faeces [52-54].

Villus height and crypt depth are reliable indicators of gut function and health. The increase of intestinal villus length can strengthen the contact between the intestine and nutrients and improve digestion and absorption. Previous studies showed that dietary supplementation with C. butyricum benefited ideal morphology in broilers [55] and dietary inclusion of a microbial feed additive (L. salivarius and L. reuteri) improved intestinal nutrient absorption which was in association with an improvement in intestinal architecture [56]. Our results showed that the intestinal mucosa, in all test groups, remained intact, the structure of each layer was clear, and the order of intestinal villi was regular. Furthermore, the effect of the two strains applied as a mixture on the length of the intestinal villi was much better than that conferred by their separate administration. These results demonstrated that the combination of the two probiotics could better affect the development of intestinal health and promote the digestion and absorption function of mice. The main reason might be that the combination of the two probiotics decreased the relative abundance of some pathogenic bacteria of the genus Enterorhabdus, Staphylococcus and Corynebacterium in the colon (Figure 5E,H,I), which can damage the intestinal mucosal epithelial cells (IECs). The other reason might be that the butyric acid, which is beneficial for IECs [57,58], was increased upon intragastric administration of $C$. butyricum (to produce butyric acid) (Table 7), and when the combined use of the two bacteria contribute to improve the family Clostridiales_vadinBB60_group (also producing butyric acid) (Figure 5C).

Enterorhabdus spp. was found in the ileitis and colitis of mice and in the human gut, which was related to inflammatory diseases $[59,60]$. Staphylococcus was associated with allergy development in the gut [61]. Some strains of Corynebacterium could induce genitourinary infection and caused a chronic contagious infectious disease of the caseous lymphadenitis or pseudotuberculosis $[62,63]$. We found that the abundances of Enterorhabdus spp., Staphylococcus spp. and Corynebacterium spp. in the colon were significantly reduced when administration the mice with the mixture of the two strains. These results further confirm that the combination use of the two strains enhances intestinal health via regulating the intestinal microflora and inhibiting harmful bacteria in the intestine.

Interestingly, we found that when the two probiotics were used together, the abundance of Tyzzerella was significantly reduced. A previous study showed that Tyzzerella was correlated with risk of cardiovascular disease [64]. Our results indicated that the combined use of the two bacteria might reduce the risk of cardiovascular disease, however, whether the simultaneous use of the two probiotics could actually reduce cardiovascular risk needs further investigation.

\section{Conclusions}

The combined use of C. butyricum Sx-01 and L. salivarius C-1-3 could significantly improve intestinal health, improve the antioxidant capacity of the body, and reduce the amount of lipids in sera of mice. The reason for this might be that besides their own probiotic effects, combined administration 
of the two strains was beneficial in that it increased the number of healthy intestinal microflora and decreased the number of harmful intestinal microflora.

Author Contributions: R.W., P.L. and J.H. conceived and designed the experiments. X.S. and J.P. performed the experiments. S.Y. and Y.Z. analysed the experimental data. M.L. wrote this paper.

Acknowledgments: This work was financially supported by the National Natural Science Foundation of China (grants No. 31640084; grants No. 31302152) and by Liaoning BaiQianWan Talents Program.

Conflicts of Interest: The authors declare no conflict of interest.

\section{References}

1. Zhang, L.; Zhan, X.; Zeng, X.; Zhou, L.; Cao, G.; Chen, A. Effects of dietary supplementation of probiotic, Clostridium butyricum, on growth performance, immune response, intestinal barrier function, and digestive enzyme activity in broiler chickens challenged with Escherichia coli K88. J. Anim. Sci. Biotechnol. 2016, 7, 3. [CrossRef] [PubMed]

2. Kong, Q.; He, G.Q.; Jia, J.L.; Zhu, Q.L.; Ruan, H. Oral administration of Clostridium butyricum for modulating gastrointestinal microflora in mice. Curr. Microbiol. 2011, 62, 512-517. [CrossRef] [PubMed]

3. Zhang, B.K.; Yang, X.; Guo, Y.M.; Long, F.Y. Effects of dietary lipids and Clostridium butyricum on the performance and the digestive tract of broiler chickens. Arch. Anim. Nutr. 2011, 65, 329-339. [CrossRef] [PubMed]

4. Tellez, G.; Pixley, C.; Wolfenden, R.E.; Layton, S.L.; Hargis, B.M. Probiotics/direct fed microbials for Salmonella control in poultry. Food Res. Int. 2012, 45, 628-633. [CrossRef]

5. Huff, G.R.; Huff, W.E.; Jalukar, S.; Oppy, J.; Rath, N.C.; Packialakshmi, B. The effects of yeast feed supplementation on turkey performance and pathogen colonization in a transport stress/Escherichia coli challenge. Poult. Sci. 2013, 92, 655-662. [CrossRef] [PubMed]

6. Liao, X.D.; Ma, G.; Cai, J.; Fu, Y.; Yan, X.Y.; Wei, X.B. Effects of Clostridium butyricum on growth performance, antioxidation, and immune function of broilers. Poult. Sci. 2015, 94, 662-667. [CrossRef] [PubMed]

7. Zhao, X.; Guo, Y.M.; Guo, S.S.; Tan, J.Z. Effects of Clostridium butyricum and Enterococcus faecium on growth performance, lipid metabolism, and cecal microbiota of broiler chickens. Appl. Microbiol. Biotechnol. 2013, 97, 6477-6488. [CrossRef] [PubMed]

8. Gao, Q.X.; Qi, L.L.; Wu, T.X.; Wang, J.B. Clostridium butyricum activates TLR2-mediated MyD88-independent signaling pathway in HT-29 cells. Mol. Cell. Biochem. 2012, 361, 31-37. [CrossRef] [PubMed]

9. Seo, M.; Inoue, I.; Tanaka, M.; Matsuda, N.; Nakano, T.; Awata, T. Clostridium butyricum MIYAIRI 588 improves high-fat diet-induced non-alcoholic fatty liver disease in rats. Dig. Dis. Sci. 2013, 58, 3534-3544. [CrossRef] [PubMed]

10. Zhang, J.; Shi, Z.L.; Zeng, M.H.; Wei, C.; Wu, H.X.; Liu, M.Y. Oral administration of Clostridium butyricum CGMCC0313-1 reduces ovalbumin-induced allergic airway inflammation in mice. Respirology 2017, 22, 898-904.

11. Shang, H.; Sun, J.; Chen, Y.Q. Clostridium butyricum CGMCC0313.1 modulates lipid profile, insulin resistance and colon homeostasis in obese Mice. PLoS ONE 2016, 11, e0154373. [CrossRef] [PubMed]

12. Sun, J.; Ling, Z.; Wang, F.; Chen, W.; Li, H.; Jin, J. Clostridium butyricum pretreatment attenuates cerebral ischemia/ reperfusion injury in mice via anti-oxidation and anti-apoptosis. Neurosci. Lett. 2016, 613, 30-35. [CrossRef] [PubMed]

13. Cassir, N.; Benamar, S.; La Scola, B. Clostridium butyricum: From beneficial to a new emerging pathogen. Clin. Microbiol. Infect. 2016, 22, 37-45. [CrossRef] [PubMed]

14. Neville, B.A.; O'Toole, P.W. Probiotic properties of Lactobacillus salivarius and closely related Lactobacillus species. Future Microbiol. 2010, 5, 759-774. [CrossRef] [PubMed]

15. Chaves, B.D.; Brashears, M.M.; Nightingale, K.K. Applications and safety considerations of lactobacillus salivarius as a probiotic in animal and human health. J. Appl. Microbiol. 2017. [CrossRef] [PubMed]

16. Chuang, C.H.; Tsai, C.C.; Lin, E.S.; Huang, C.S.; Lin, Y.Y.; Lan, C.C. Heat-killed Lactobacillus salivarius and Lactobacillus johnsonii reduce liver injury induced by alcohol in vitro and in vivo. Molecules 2016, 21, 1456. [CrossRef] [PubMed] 
17. Lv, L.X.; Yan, R.; Shi, H.Y.; Shi, D.; Fang, D.Q.; Jiang, H.Y. Integrated transcriptomic and proteomic analysis of the bile stress response in probiotic Lactobacillus salivarius LI01. J. Proteom. 2017, 150, 216-229. [CrossRef] [PubMed]

18. Tinrat, S.; Saraya, S.; Traidej Chomnawang, M. Isolation and characterization of Lactobacillus salivarius MTC 1026 as a potential probiotic. J. Gen. Appl. Microbiol. 2011, 57, 365-378. [CrossRef] [PubMed]

19. Zhang, J.; Deng, J.; Wang, Z.; Che, C.; Li, Y.F.; Yang, Q. Modulatory effects of Lactobacillus salivarius on intestinal mucosal immunity of piglets. Curr. Microbiol. 2011, 62, 1623-1631. [CrossRef] [PubMed]

20. Chen, X.L.; Shao, Q.B.; Wang, C.; He, J.B.; Zhang, Y.; Yang, S.H. Isolation and Identification of Lactobacillus salivarius from chicken intestine and its biological characteristics. Food Sci. 2016, 37, 157-161.

21. Thanh, N.; Loh, T.C.; Foo, H.L.; Hair-Bejo, M.; Azhar, B. Effects of feeding metabolite combinations produced by Lactobacillus plantarum on growth performance, faecal microbial population, small intestine villus height and faecal volatile fatty acids in broilers. Br. Poult. Sci. 2009, 50, 298-306. [CrossRef] [PubMed]

22. Kareem, K.Y.; Loh, T.C.; Foo, H.L.; Akit, H.; Samsudin, A.A. Effects of dietary postbiotic and inulin on growth performance, IGF1 and GHR mRNA expression, faecal microbiota and volatile fatty acids in broilers. BMC Vet. Res. 2016, 12, 163. [CrossRef] [PubMed]

23. Jeong, S.Y.; Im, Y.N.; Youm, J.Y.; Lee, H.K.; Im, S.Y. 1-Glutamine Attenuates DSS-Induced Colitis via Induction of MAPK Phosphatase-1. Nutrients 2018, 10, 288. [CrossRef] [PubMed]

24. Guan, Y.; Yang, H.; Han, S.; Feng, L.; Wang, T.; Ge, J. Comparison of the gut microbiota composition between wild and captive sika deer (Cervus nippon hortulorum) from feces by high-throughput sequencing. $A M B$ Express 2017, 7, 212. [CrossRef] [PubMed]

25. Magoč, T.; Salzberg, S.L. FLASH: Fast length adjustment of short reads to improve genome assemblies. Bioinformatics 2011, 27, 2957-2963. [CrossRef] [PubMed]

26. Bolger, A.M.; Lohse, M.; Usadel, B. Trimmomatic: A flexible trimmer for Illumina sequence data. Bioinformatics 2014, 30, 2114-2120. [CrossRef] [PubMed]

27. Phuoc, T.L.; Jamikorn, U. Effects of probiotic supplement (Bacillus subtilis and Lactobacillus acidophilus) on feed efficiency, growth performance, and microbial population of weaning rabbits. Asian-Australas. J. Anim. Sci. 2017, 30, 198-205. [CrossRef] [PubMed]

28. Hossain, M.M.; Begum, M.; Kim, I.H. Effect of Bacillus subtilis, Clostridium butyricum and Lactobacillus acidophilus endospores on growth performance, nutrient digestibility, meat quality, relative organ weight, microbial shedding and excreta noxious gas emission in broilers. Vet. Med. 2015, 60, 77-86. [CrossRef]

29. Giang, H.H.; Viet, T.Q.; Ogle, B.; Lindberg, J.E. Effects of Supplementation of Probiotics on the Performance, Nutrient Digestibility and Faecal Microflora in Growing-finishing Pigs. Asian-Australas. J. Anim. Sci. 2011, 24, 655-661. [CrossRef]

30. Miao, R.X.; Zhu, X.X.; Wan, C.M.; Wang, Z.L.; Wen, Y.; Li, Y.Y. Effect of Clostridium butyricum supplementation on the development of intestinal flora and the immune system of neonatal mice. Exp. Ther. Med. 2018, 15, 1081-1086. [PubMed]

31. Steinberg, R.S.; Lima, M.; Gomes de Oliveira, N.L.; Miyoshi, A.; Nicoli, J.R.; Neumann, E. Effect of intestinal colonisation by two Lactobacillus strains on the immune response of gnotobiotic mice. Benef. Microbes 2014, 5, 409-419. [CrossRef] [PubMed]

32. Cassir, N.; Benamar, S.; Khalil, J.B.; Croce, O.; Saint-Faust, M.; Jacquot, A. Clostridium butyricum Strains and Dysbiosis Linked to Necrotizing Enterocolitis in Preterm Neonates. Clin. Infect. Dis. 2015, 61, 1107-1115. [CrossRef] [PubMed]

33. Sato, Y.; Kujirai, D.; Emoto, K.; Yagami, T.; Yamada, T.; Izumi, M. Necrotizing enterocolitis associated with Clostridium butyricum in a Japanese man. Acute Med. Surg. 2018, 5, 194-198. [CrossRef] [PubMed]

34. Benamar, S.; Cassir, N.; Merhej, V.; Jardot, P.; Robert, C.; Raoult, D. Multi-spacer typing as an effective method to distinguish the clonal lineage of Clostridium butyricum strains isolated from stool samples during a series of necrotizing enterocolitis cases. J. Hosp. Infect. 2017, 95, 300-305. [CrossRef] [PubMed]

35. Chen, F.; Gao, S.S.; Zhu, L.Q.; Qin, S.Y.; Qiu, H.L. Effects of dietary Lactobacillus rhamnosus CF supplementation on growth, meat quality, and microenvironment in specific pathogen-free chickens. Poult. Sci. 2018, 97, 118-123. [CrossRef] [PubMed]

36. Jeong, J.S.; Kim, I.H. Effect of Bacillus subtilis C-3102 spores as a probiotic feed supplement on growth performance, noxious gas emission, and intestinal microflora in broilers. Poult. Sci. 2014, 93, 3097-3103. [CrossRef] [PubMed] 
37. Zhang, Z.F.; Kim, I.H. Effects of multistrain probiotics on growth performance, apparent ileal nutrient digestibility, blood characteristics, cecal microbial shedding, and excreta odor contents in broilers. Poult. Sci. 2014, 93, 364-370. [CrossRef] [PubMed]

38. Menard, S.; Candalh, C.; Bambou, J.C.; Terpend, K.; Cerf-Bensussan, N.; Heyman, M. Lactic acid bacteria secrete metabolites retaining anti-inflammatory properties after intestinal transport. Gut 2004, 53, 821-828. [CrossRef] [PubMed]

39. Han, J.F.; Wang, Y.W.; Song, D.; Lu, Z.X.; Dong, Z.L.; Miao, H.J. Effects of Clostridium butyricum and Lactobacillus plantarum on growth performance, immune function and volatile fatty acid level of caecal digesta in broilers. Food Agric. Immunol. 2018. [CrossRef]

40. Alhidary, I.A.; Abdelrahman, M.M.; Khan, R.U. Comparative effects of direct-fed microbials alone or with a trace minerals supplements on the productive performance, blood metabolites, and antioxidant status in grazing Awassi lambs. Environ. Sci. Pollut. Res. 2016, 23, 25218-25223. [CrossRef] [PubMed]

41. Saleem, A.M.; Zanouny, A.I.; Singer, A.M. Growth performance, nutrients digestibility, and blood metabolites of lambs fed diets supplemented with probiotics during pre- and post-weaning period. Asian-Australas. J. Anim. Sci. 2017, 30, 523-530. [CrossRef] [PubMed]

42. Shen, X.; Yi, D.; Ni, X.; Zeng, D.; Jing, B.; Lei, M. Effects of Lactobacillus plantarum on production performance, immune characteristics, antioxidant status, and intestinal microflora of bursin-immunized broilers. Can. J. Microbiol. 2014, 60, 193-202. [CrossRef] [PubMed]

43. Wang, H.; Ni, X.; Qing, X.; Liu, L.; Xin, J.; Luo, M. Probiotic Lactobacillus johnsonii BS15 improves blood parameters related to immunity in broilers experimentally infected with subclinical necrotic enteritis. Front. Microbiol. 2018, 9, 49. [CrossRef] [PubMed]

44. Aluwong, T.; Kawu, M.; Raji, M.; Dzenda, T.; Govwang, F.; Sinkalu, V. Effect of yeast probiotic on growth, antioxidant enzyme activities and malondialdehyde concentration of broiler chickens. Antioxidants 2013, 2, 326-339. [CrossRef] [PubMed]

45. Liao, X.; Wu, R.; Ma, G.; Zhao, L.; Zheng, Z.; Zhang, R. Effects of Clostridium butyricum on antioxidant properties, meat quality and fatty acid composition of broiler birds. Lipids Health Dis. 2015, 14, 36. [CrossRef] [PubMed]

46. Zhao, Y.; Zhao, L.; Zheng, X.; Fu, T.; Guo, H.; Ren, F. Lactobacillus salivarius strain FDB89 induced longevity in Caenorhabditis elegans by dietary restriction. Microbiology 2013, 51, 183-188. [CrossRef] [PubMed]

47. Kullisaar, T.; Songisepp, E.; Mikelsaar, M.; Zilmer, K.; Vihalemm, T.; Zilmer, M. Antioxidative probiotic fermented goats' milk decreases oxidative stress-mediated atherogenicity in human subjects. Br. J. Nutr. 2003, 90, 449-456. [CrossRef] [PubMed]

48. Junghare, M.; Subudhi, S.; Lal, B. Improvement of hydrogen production under decreased partial pressure by newly isolated alkaline tolerant anaerobe, Clostridium butyricum TM-9A: Optimization of process parameters. Int. J. Hydrogen Energy 2012, 37, 3160-3168. [CrossRef]

49. Famouri, F.; Shariat, Z.; Hashemipour, M.; Keikha, M.; Kelishadi, R. Effects of Probiotics on Nonalcoholic Fatty Liver Disease in Obese Children and Adolescents. J. Pediatr. Gastroenterol. Nutr. 2017, 64, 413-417. [CrossRef] [PubMed]

50. Karamali, M.; Dadkhah, F.; Sadrkhanlou, M.; Jamilian, M.; Ahmadi, S.; Tajabadi-Ebrahimi, M. Effects of probiotic supplementation on glycaemic control and lipid profiles in gestational diabetes: A randomized, double-blind, placebo-controlled trial. Diabetes Metab. 2016, 42, 234-241. [CrossRef] [PubMed]

51. Kalavathy, R.; Abdullah, N.; Jalaludin, S.; Wong, M.; Ho, Y.W. Effects of Lactobacillus feed supplementation on cholesterol, fat content and fatty acid composition of the liver, muscle and carcass of broiler chickens. Anim. Res. 2006, 55, 77-82.

52. Li, L.; Baumann, C.A.; Meling, D.D.; Sell, J.L.; Beitz, D.C. Effect of orally administered Eubacterium coprostanoligenes ATCC 51222 on plasma cholesterol concentration in laying hens. Poult. Sci. 1996, 75, 743-745. [CrossRef] [PubMed]

53. Ren, D.; Li, L.; Schwabacher, A.W.; Young, J.W.; Beitz, D.C. Mechanism of cholesterol reduction to coprostanol by Eubacterium coprostanoligenes ATCC 51222. Steroids 1996, 61, 33-40. [CrossRef]

54. Koppel, N.; Maini, R.V.; Balskus, E.P. Chemical transformation of xenobiotics by the human gut microbiota. Science 2017, 356, eaag2770. [CrossRef] [PubMed] 
55. Cao, G.T.; Xiao, Y.P.; Yang, C.M.; Chen, A.G.; Liu, T.T.; Zhou, L. Effects of Clostridium butyricum on growth performance, nitrogen metabolism, intestinal morphology and cecal microflora in broiler chickens. J. Anim. Vet. Adv. 2012, 11, 2665-2671.

56. Awad, W.A.; Ghareeb, K.; Böhm, J. Effect of addition of a probiotic micro-organism to broiler diet on intestinal mucosal architecture and electrophysiological parameters. J. Anim. Physiol. Anim. Nutr. (Berl.) 2010, 94, 486-494. [CrossRef] [PubMed]

57. Kumar, A.; Alrefai, W.A.; Borthakur, A.; Dudeja, P.K. Lactobacillus acidophilus counteracts enteropathogenic E. coli-induced inhibition of butyrate uptake in intestinal epithelial cells. Am. J. Physiol. Gastrointest. Liver Physiol. 2015, 309, G602-G607. [CrossRef] [PubMed]

58. Ma, X.; Fan, P.X.; Li, L.S.; Qiao, S.Y.; Zhang, G.L.; Li, D.F. Butyrate promotes the recovering of intestinal wound healing through its positive effect on the tight junctions. J. Anim. Sci. 2012, 90 (Suppl. 4), 266-268. [CrossRef] [PubMed]

59. Hov, J.R.; Zhong, H.; Qin, B.; Anmarkrud, J.A.; Holm, K.; Franke, A. The Influence of the Autoimmunity -Associated Ancestral HLA Haplotype AH8.1 on the Human Gut Microbiota: A Cross-Sectional Study. PLoS ONE 2015, 10, e0133804. [CrossRef] [PubMed]

60. Clavel, T.; Charrier, C.; Braune, A.; Wenning, M.; Blaut, M.; Haller, D. Isolation of bacteria from the ileal mucosa of TNFdeltaARE mice and description of Enterorhabdus mucosicola gen. nov., sp. nov. Int. J. Syst. Evol. Microbiol. 2009, 59, 1805-1812. [CrossRef] [PubMed]

61. Björkstén, B.; Sepp, E.; Julge, K.; Voor, T.; Mikelsaar, M. Allergy development and the intestinal microflora during the first year of life. J. Allergy Clin. Immunol. 2001, 108, 516-520. [CrossRef] [PubMed]

62. Poor, A.P.; Moreno, L.Z.; Matajira, C.E.C.; Parra, B.M.; Gomes, V.T.M.; Silva, A.P.S. Characterization of Corynebacterium diphtheriae, C. confusum and C. amycolatum isolated from sows with genitourinary infection. Vet. Microbiol. 2017, 207, 149-152. [CrossRef] [PubMed]

63. Guerrero, J.A.V.; de Oca Jiménez, R.M.; Acosta Dibarrat, J.; León, F.H.; Morales-Erasto, V.; Salazar, H.G.M. Isolation and molecular characterization of Corynebacterium pseudotuberculosis from sheep and goats in Mexico. Microb. Pathog. 2018, 117, 304-309. [CrossRef] [PubMed]

64. Kelly, T.N.; Bazzano, L.A.; Ajami, N.J.; He, H.; Zhao, J.; Petrosino, J.F. Gut Microbiome Associates with Lifetime Cardiovascular Disease Risk Profile Among Bogalusa Heart Study Participants. Circ. Res. 2016, 119, 956-964. [CrossRef] [PubMed] 